12. Bell E.F., McIntosh D.H., Katz N., Weinberg M.D. The optical and near-infrared properties of galaxies. I. Luminosity and stellar mass function // Astroph. J. Suppl. Ser. - 2003. - V. 149. - P. 289-312.

13. Karachentsev I.D., Makarov D.I. Galaxy interactions in the Local volume // IAUS. - 1999. - V. 186. - P. $109-116$.

14. Navarro J.F., Frenk C.S., White S.D.M. An universal density profile from hierarchical clustering // Astroph. J. - 1997. - V. 490. - P. 493-508.

15. Klypin A., Zhao Hong Shen, Sommerwille R.S. ACDM-based models for the Milky Way and M31. I. Dynamical Models // Astroph. J. - 2002. - Vol. 573, Is.2. - P. 597-613.

Надійшла до редколегії 30.08.15

Kudrya Ju., Ph.D.

Astronomical Observatory of National

Taras Shevchenko University of Kyiv

\title{
DARK MATTER DISTRIBUTION IN HALOES OF NEARBY GIANT GALAXIES
}

The profiles of orbital mass growth depending on the tidal index and the profiles of dark matter halos density were built based on kinematics of the satellites of four nearby giant galaxy (M81, NGC 3368, Milky Way, M31). Parts of the dark matter halo between virial radii and radii of the zero velocity surface are estimated.

Кудря Ю., канд. физ.- мат. наук

Астрономическая обсерватория

Киевского национального университета имени Тараса Шевченко

\section{РАСПРЕДЕЛЕНИЕ ТЕМНОЙ МАТЕРИИ В ГАЛО БЛИЗКИХ ГИГАНТСКИХ ГАЛАКТИК}

Для четирех близких гигантских галактик (M81, NGC3368, Млечный Путь, М31) по кинематике их спутников построены профили роста орбитальных масс в зависимости от приливного индекса, а также профили плотности темной материи в гало. Оценены части массы гало между вириальными радиусами и радиусами поверхности нулевой скороости.

УДК 524.7

С. Парновський, д-р. фіз.-мат. наук, І. Ізотова, канд. фіз.-мат. наук Астрономічна обсерваторія Київського національного університету імені Тараса Шевченка

\section{ПОЧАТКОВІ ФУНКЦІЇ СВІТНОСТІ ГАЛАКТИК З АКТИВНИМ ЗОРЕУТВОРЕННЯМ}

Розелянуто початкові функції світності, які описують розподіл світності галактик у рекомбінаційній лінії На у зонах іонізованого водню та ультрафіолетовому континуумі при нульовому віці спалаху, для вибірки 800 галактик з активним зореутворенням. Показано, що початкові функції світності галактик з активним зореутворенням у лінії На та ультрафіолетовому континуумі можуть бути задовільно описані log-нормальною функцією, яка описує і поточні функції світності.

Функція світності (ФС), яка описує розподіл світності галактик, є важливою статистичною характеристикою населення галактик. Зазвичай у якості ФС обирають функцію Шехтера (ФШ) [22], яка відома у математичній статистиці як гамма фрункція.

У низці робіт проведено дослідження ФС галактик у різних діапазонах випромінювання: на 60 мкм у далекому інфррачервоному діапазоні $[13,21,23]$; для вибірки близько 50 тис галактик з червоним зміщенням $z \leq 0.1$ [20] в ультрафріолетовому (УФ) діапазоні на основі розподілу відношення швидкості зореутворення, яка пропорційна світності, до маси; у радіоконтинуумі $[7,15,24]$. При цьому встановлено, що досліджувані ФС не можуть бути апроксимовані функцією Шехтера. Такий же результат отримано для області високих світностей вибірки 34 світних галактик на великих червоних зміщеннях [5]. У роботі [10] на основі дослідження функцій світності галактик з використанням даних місії GALEX та WiggleZ Dark Energy Survey при z > 0.55 виявлено надлишок світних галактик, якщо порівнювати 3 розподілом Шехтера.

У той же час функція Шехтера гарно відтворює ФС у оптичному та близькому інфрачервоному діапазонах, у рекомбінаційній лінії На у областях іонізованого водню [8, 14], та УФ діапазоні [25].

Автори робіт $[1,16,17,18]$ детально досліджували фрункції світності вибірки 800 галактик зі спалахом зореутворення. Було показано, що ФС, які отримано зі спостережень випромінювання галактик 3 активним зореутворенням у рекомбінаційній лінії На, далекому та близькому ультрафіолетовому континуумі, суттєво відрізняються від функції Шехтера. Було запропоновано ряд функцій, які задовільно описують спостережну ФС досліджуваних галактик, у числі яких $є \log$-нормальна функція.

Функцію світності типу функції Шехтера, остання базується на розподілі Пуассона, можна очікувати у випадку незалежності ймовірності зореутворення у двох сусідніх близьких областях галактик. Отриманий у роботах [1, 16, 17, 18] результат - відмінність спостережної ФС від функції Шехтера - свідчить на користь зкорельованності процесів зореутворення у близьких сусідніх областях галактики. Надлишок числа галактик 3 високою світністю $\left(L(\mathrm{H \alpha})>5 \times 10^{42}\right.$ ерг·c $\left.{ }^{-1}\right)$, який виявлено у роботах $[1,16,17,18]$, ймовірно, можна віднести за рахунок поширення зореутворення на сусідні області галактики, простимульованого спалахом зореутворення у певному осередку.

Дослідження у роботах $[1,16,17,18]$ проведено для випадку, коли початкова ФС представлена функцією Шехтера. У цій роботі розглянуто випадок апроксимації початкової функції світності вибірки 800 галактик з активним зореутворенням log-нормальним розподілом у трьох діапазонах: рекомбінаційній лінії На та ультрафріолетовому континуумі (FUV далекому та NUV близькому).

Для дослідження ми використовували ту ж вибірку галактик з активним зореутворенням [9], що і у роботах [1, 16, 17, 18]. Це - вибірка компактних галактик великої світності (LCGs), z $0.02-0.6$, утворена на основі даних Sloan Digital Sky Survey (SDSS) [2]. 
Детальний опис критеріїв відбору вибірки LCGs галактик приведено у роботах $[9,17]$. Відзначимо принципові позиції відбору: LCGs мають компактні розміри $\left(\leq 10^{\prime \prime}\right)$ та низький вміст важких елементів $(12+\operatorname{logO} / \mathrm{H} \sim 7.6-8.4)$; їх світність та еквівалентна ширина в емісійній лінії $\mathrm{H \beta}$ в зонах $\mathrm{HIl} \in L(\mathrm{H} \beta) \geq 3 \times 10^{40}$ ерг c ${ }^{-1} \mathrm{Ta} E W(\mathrm{H} \beta) \geq 50 \AA$ i $E W(H \beta) \geq 100 \AA$, відповідно, що свідчить про наявність сильного і "молодого" спалаху зореутворення; на діагностичній діаграмі $[3,11]$ LCGs галактики займають область, яка притаманна зонам НII високої іонізації, у них відсутні спектральні ознаки наявності активних ядер.

Галактики вибірки було ототожнено з джерелами випромінювання у далекому (FUV, $\left.\lambda_{\text {eff }}=1528 \AA\right)$ та близькому (NUV, $\lambda_{\text {eff }}=2271 \AA$ ) ультрафріолетовому континуумі за даними спостережень місії GALEX.

Світності галактик у трьох діапазонах (рекомбінаційній лінії На, ультрафіолетовому FUV та NUV континуумі) було отримано з належним врахуванням екстинкції випромінювання та корекцією за апертуру спостережень (див. всі деталі у [17]). 3 врахуванням висновків роботи [19], корекції було проведено індивідуально для кожної галактики. Для обчислення світності галактик прийнято значення постійної Хаббла $\mathrm{H}_{0}=75 \mathrm{~km} \mathrm{сек}^{-1} \cdot \mathrm{Mn \kappa}^{-1}$.

У роботі [17] було показано, що у LCGs відношення SFR/m швидкості зореутворення SFR, пропорційної світності галактики в певному діапазоні $[6,12]$, до маси $m$ молодого зоряного населення як функція віку $T$ спалаху зореутворення стрімко падає на шкалі часу менше $10 \mathrm{mлн} \mathrm{років.} \mathrm{Використані} \mathrm{параметри} m$ та $T$ для LCGs галактик було визначено у роботі [9] на основі дослідження спектрального розподілу енергії у діапазоні $\lambda \lambda 3800-9200 \AA$. Світність галактики $L(T) \in$ максимальною відразу після спалаху зореутворення, і починає спадати в процесі еволюції масивних зір, які мають відносно короткий вік життя. Це особливо виразно прослідковується для випромінювання у рекомбінаційній лінії На та FUV континуумі, і з більшою дисперсією - у NUV континуумі. Цю коротко-термінову еволюцію світності галактик можна описати наступним чином:

$$
L(T)=L_{0} \times f(T), \quad f(T)=\left\{\begin{array}{ll}
1 & T \leq T_{0} \\
\exp \left(-p\left(T-T_{0}\right)\right) & T>T_{0}
\end{array},\right.
$$

де $T$ - проміжок часу після спалаху зореутворення, $L_{0}$ - світність галактики при $T=0$. У роботі [17] було детально проаналізовано функцію $f(T)$, встановлено, що $T_{0}=3.2 \mathrm{Mлн} \mathrm{років,} \mathrm{і} \mathrm{значення} \mathrm{параметра} p=0.75$ (млн років) ${ }^{-1}$; $p=0.43$ (млн років) ${ }^{-1}$ та $p=0.33$ (млн років) $)^{-1}$ для випромінювання у рекомбінаційній лінії Нa, FUV та NUV континуумі, відповідно. Детальні розрахунки та значення параметрів для різних вибірок та діапазонів випромінювання наведено у табл. 5 [17].

Розглянемо початкову функцію світності $n\left(L_{0}\right)$. Вона описує розподіл світностей $L_{0}$ (світності галактик при $T=0$ ) галактик вибірки. Тоді $n\left(L_{0}\right) \mathrm{d} L_{0}$ - це кількість спалахів зореутворення в інтервалі початкових світностей від $L_{0}$ до $L_{0}+\mathrm{d} L_{0}$. Для того, щоб визначити цей розподіл, ми стандартним чином розрахували для кожної галактики їі L поточну світність (за випромінюванням у лінії Ha, FUV та NUV континуумі), врахувавши вплив екстинкції та інших факторів, процедура, як уже зазначалось, докладно описана у [17]. Потім за даними про цю величину та віком спалаху зореутворенння $T$, отриманого в [9], з врахуванням рівняння (1) і відповідних значень параметрів $p$, визначених для кожного діапазону випромінювання [17], визначалась $L_{0}$ початкова світність кожної галактики. Отриманий спостережний розподіл $n\left(L_{0}\right)$ було апроксимовано різними функціями. Найбільш якісне наближення дає застосування log-нормального розподілу:

$$
n\left(L_{0}\right)=\left(\frac{a}{\pi}\right)^{1 / 2} \exp \left(-\frac{1}{4 a}\right) \tilde{L}^{-1} \exp \left(-a \ln ^{2}\left(L_{0} / \tilde{L}\right)\right)=\left(\frac{a}{\pi}\right)^{1 / 2} \exp \left(-\frac{1}{4 a}\right) \tilde{L}^{-1}\left(\frac{L_{0}}{\tilde{L}}\right)^{-a \ln \left(L_{0} / \tilde{L}\right)} .
$$

Оптимальні значення параметрів (2) знаходяться за формулами з роботи [16]. Для розподілу $L_{0}$ початкової світності у рекомбінаційній лінії На отримуємо $\tilde{L}=3.99 \times 10^{41}$ ерг·c ${ }^{-1}, a=0.425$, для розподілу $L_{0}$ початкової світності у $F U V$ та

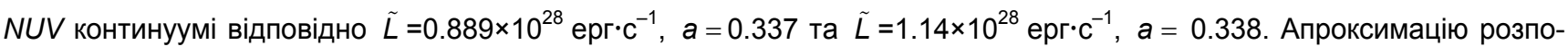
ділу $L_{0}$ початкової світності випромінювання галактик з активним зореутворенням у рекомбінаційній лінії На, ультрафіолетовому FUV та NUV континуумі log-нормальними функціями приведено на рис.1-3 (суцільна лінія). Як видно $з$ рис. 1-3, log-нормальні функції адекватно відтворюють розподіл $L_{0}$ початкової світності галактик у трьох діапазонах випромінювання. Для порівняння також приведено апроксимації розподілу log-нормальними фуункціями $L$ поточної світності (штрихована лінія). 3 рис.1-3 видно, що для випромінювання у FUV та особливо NUV континуумі, де менші величини параметру $р$ з (1), різниця в розподілі $L$ поточних та $L_{0}$ початкових світностей менша, ніж для аналогічних розподілів у лінії На, у якої значення параметру $р$ найвище.

На рис. 4-6 приведено також розподіл $L_{0} / m$ відношення $L_{0}$ початкової світності до $m$ маси молодого зоряного населення у лінії На та зазначених УФ діапазонах. Як видно з рис. $4, L_{0} / m$ відношення для випромінювання у лінії На $€$ набагато стабільнішим, ніж для випромінювання в УФ континуумі (рис. 5-6). Розподіл $L_{0} / m$ для лінії На виявляє досить вузьку середню частину, подібну до log-нормального розподілу, на тлі більш широких крил.

Розподіл $L_{0} / m$ відношення $L_{0}$ початкової світності до $m$ маси для молодого зоряного населення, отриманий за випромінюванням в УФ континуумі, не є особливо інформативним через більші похибки вимірювання потоків, що розмивають отримані графіки залежностей. Але для випромінювання у лінії На ми отримали набагато більш вузький профріль з широкими крилами. Отриману залежність можна розглядати як імовірний натяк на існування декількох механізмів відхилення відношення $L_{0} / m$ від середнього значення. Один з них забезпечує відносно вузький профіль 3 нормальним або log-нормальним відхиленням. Левова частина галактик відноситься саме до цієї області. Незначна кількість галактик має більші відхилення від середнього, вона лежить у області більш широких крил розподілу. Якщо це не є артефактом, пов'язаним з похибками спостережень, моделювання або опрацювання, то це може бути свідченням на користь існування деякого процесу, що може забезпечувати значне відхилення відношення світності до маси для незначної частини спалахів зореутворення. Як можливу гіпотетичну причину наведемо відхилення початкової функції розподілу мас (IMF) зір, що утворюються при такому спалаху, від середньої IMF. Виявлений фракт потребує подальшого дослідження. 


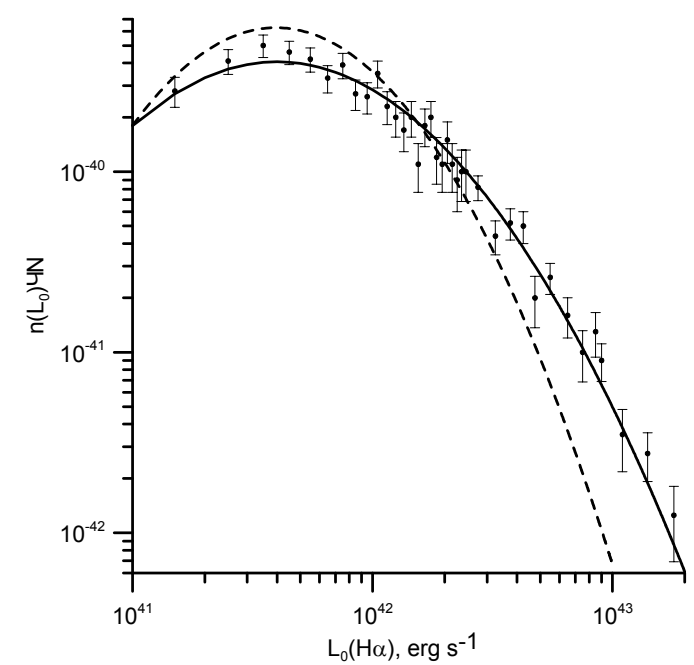

Рис. 1. Розподіл початкової $L_{0}$ світності у рекомбінаційній лінії На. Для $L_{0}$ початкової та $L$ поточної світності [18] апроксимації log-нормальними функціями (кожна зі своїми параметрами) приведені суцільною та штрихованою лініями, відповідно. Похибки відповідають розподілу Пуассона

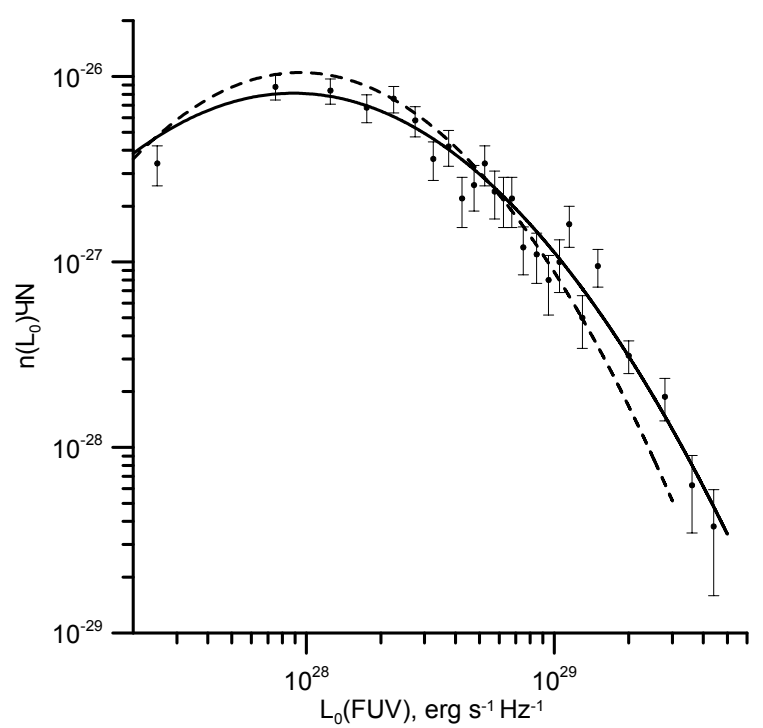

Рис. 2. Те ж, що рис. 1, але для FUV континууму

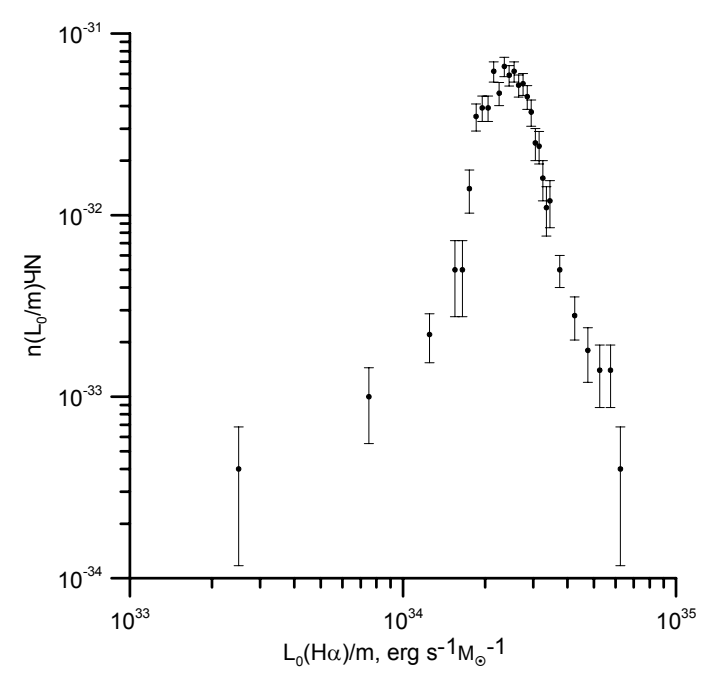

Рис. 4. Розподіл $L_{0} / m$, відношення $L_{0}$ початкової світності до $m$ маси молодого зоряного населення за випромінюванням у рекомбінаційній лінії На. Похибки відповідають розподілу Пуассона 


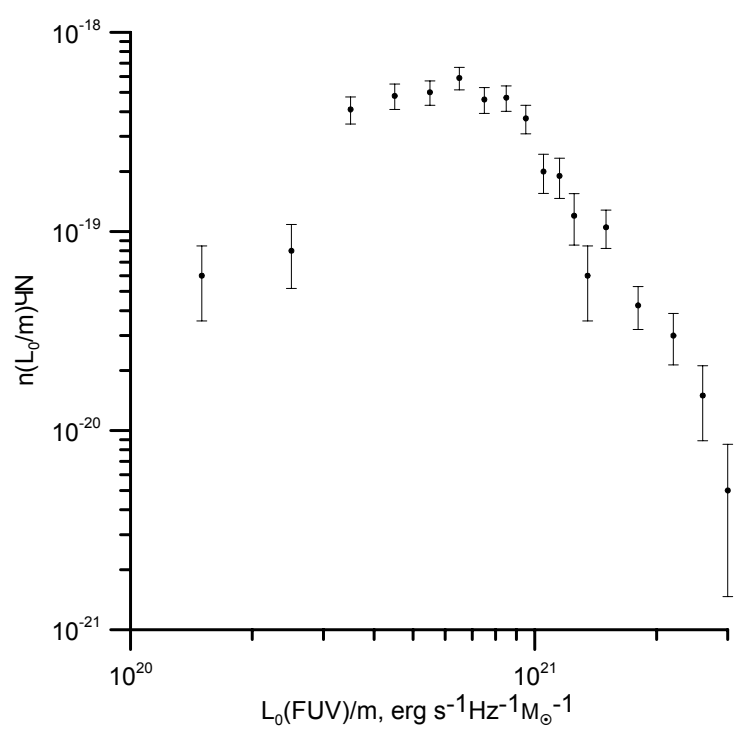

Рис. 5. Те ж, що рис. 4, але для FUV континууму

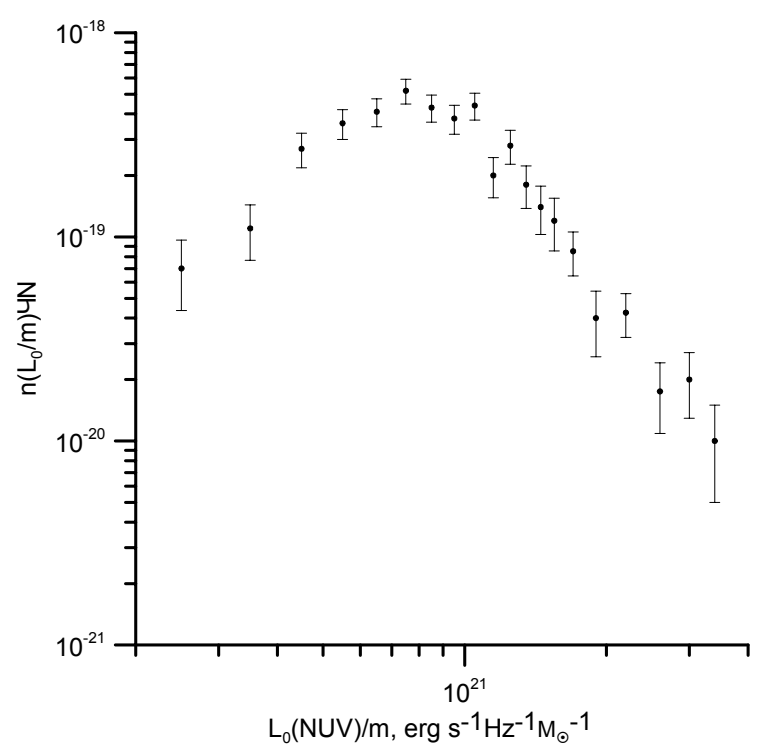

Рис. 6. Tе ж, що рис. 4, але для NUV континууму

Висновки. Для вибірки галактик з активним зореутворенням показано, що розподіл $L_{0}$ початкової світності випромінювання галактик у рекомбінаційній лінії Ha, FUV далекому та NUV близькому УФ континуумі задовільно апроксимується log-нормальною функцією. Таку ж задовільну апроксимацію log-нормальними функціями зі своїми параметрами та порідненими з ним функціями, описаними у $[16,18]$, але відмінну від функції Шехтера, якій притаманна нестача кількості галактик на яскравому кінці розподілу, було отримано і для розподілу $L$ поточної світності випромінювання у лінії Ha, FUV та NUV континуумі галактик даної вибірки у роботі [18]. Отриманий результат ще раз підтверджує висновки роботи [18]. В чому полягає різниця між підходами, що застосовані у роботі [18] та у цій статті? У роботі [16] було встановлено статистичний зв'язок між розподілом початкових та поточних світностей. У роботі [18] за різними припущеннями щодо початкової функції світності було розраховано відповідні розподіли поточних світностей, які порівняно зі спостережними. У нашій роботі для кожної окремої галактики безпосередньо розраховано її початкову світність без застосування усереднень за часом або за вибіркою. Але при цьому слід зазначити, що у розрахунках використано формулу (1), яка є вірною лише статистично. Таким чином, обидва методи мають свої вади та переваги, але вони, очевидно, є різними. Їх можна в якомусь сенсі порівняти до розв'язку прямих та обернених задач у математиці.

Розподіл $L_{0} / m$ відношення $L_{0}$ початкової світності до $m$ маси для молодого зоряного населення, що утворилося при спалаху зореутворення, розглядається вперше. Відмінності у розподілі $L_{0} / m$, отримані за спостереженнями у лінії На з одного боку та FUV та NUV континуумі з іншого, потребують подальшого дослідження.

Список використаних джерел

1. Парновський С., Ізотова І. Мультихвильові функції світності галактик з активним зореутворенням // Вісник Київського національного університету імені Тараса Шевченка. Астрономія. - 2015. - Вип. (1)52. - С. 15-23.

2. Abazajian, K.N., Adelman-McCarthy J. K., Agüeros M. A. et al. The Seventh Data Release of the Sloan Digital Sky Survey // Astrophys. J. Suppl. Ser. - 2009. - V. 182. - P. 543-558.

3. Baldwin J.A., Phillips M.M., Terlevich R. Classification parameters for the emission-line spectra of extragalactic objects // Publ. Astron. Soc. Pac. - 1981.- V. 93. - P. 5-19.

4. Blanton, M. R., Hogg, D. W, Bahcall, N. A., et al. The Galaxy Luminosity Function and Luminosity Density at Redshift z $=0.1 / /$ Astrophys. J. -2003 . V. 592. - P. 819-838.

5. Bowler, R. A. A., Dunlop, J. S, McLure, R. J., et al. The bright end of the galaxy luminosity function at $z \sim=7$ : before the onset of mass quenching? // Mon. Not. Roy. Astron. Soc. -2014.- V. 440, Issue 3. - P. 2810-2842.

6. Calzetti D. Star formation rate indicators // preprint arXiv:1208.2997v1.

7. Condon J. J., Cotton, W. D. , Broderick, J. J. Radio Sources and Star Formation in the Local Universe// Astron. J. - 2002. - V. 124, Issue 2. - P. 675-689.

8. Gallego, J., Zamorano, J., Aragon-Salamanca, A., Rego, M. The Current Star Formation Rate of the Local Universe // Astrophys. J. Lett. - 1996. V. 459. - P. L43. 13

9. Izotov Y. I., Guseva N.G., Thuan T.X. Green Pea Galaxies and Cohorts: Luminous Compact Emission-line Galaxies in the Sloan Digital Sky Survey // Astrophys. J. - 2011. - V. $728-$ P. 161-177.

10. Jurek, R. J., Drinkwater, M. J., Pimbblet, K., et al. The WiggleZ Dark Energy Survey: star formation in UV-luminous galaxies from their luminosity functions // Mon. Not. Roy. Astron. Soc. - 2013.- V. 434, Issue 1. - P. 257-281.

11. Kauffmann G., Heckman T. M., Tremonti C. et al. The host galaxies of active galactic nuclei // Mon. Not. Roy. Astron. Soc. - 2003. - V. 346. - P. 1055-1077.

12. Kennicutt R. C., Jr. Star Formation in Galaxies along the Hubble Sequence // Ann. Rev. Astron. Astrophys. - 1998. - V. 36. - P. 189-232.

13. Lawrence, A., Walker, D., Rowan-Robinson, M., et al. Studies of IRAS sources at high galactic latitudes. II - Results from a redshift survey at B greater than 60 deg: Distribution in depth, luminosity function, and physical nature of IRAS galaxies // Mon. Not. Roy. Astron. Soc. -1986. - V. 219. - P. 687-701.

14. Ly, C., Lee, J. C., Dale, D. A., et al. The Halpha Luminosity Function and Star Formation Rate Volume Density at $z=0.8$ from the NEWFIRM Halpha Survey // Astrophys. J. - 2011. - V.726, Issue 2 - article id. 109, 19 pp.

15. Machalski, J., Godlowski, W. $1.4 \mathrm{GHz}$ luminosity function of galaxies in the Las Campanas redshift survey and its evolution // Astron. Astrophys. -2000. - V. 360. -P. 463-471.

16. Parnovsky S.L. Impact of the short-term luminosity evolution on luminosity function of star-forming galaxies // Astrophysics and Space Science. - 2015 . - V. 360, article id.4, 6 pp.

17. Parnovsky S.L., Izotova I.Yu., Izotov Y.I. Ha and UV luminosities and star formation rates of large sample of luminous compact galaxies // Astrophysics and Space Science. - 2013. - N 343. - P. 361-376.

18. Parnovsky S.L., Izotova I.Yu. Luminosity function of luminous compact star-forming galaxies // Astrophysics and Space Science. - 2016. - V.361.- issue 3 .

19. Salim, S., Lee J. C. Star Formation Rate Distributions: Inadequacy of the Schechter Function // Astrophys. J. - 2012. - V. 758, Issue 2. - article id. 134.

20. Salim, S., Rich R. M., Charlot S., et al. UV Star Formation Rates in the Local Universe // Astrophys. J.Supp.Ser. - 2007. - V.173, Issue 2. - P. 267-292. 
21. Saunders, W., Rowan-Robinson, M., Lawrence, A., et al. The 60-micron and far-infrared luminosity functions of IRAS galaxies // Mon. Not. Roy. Astron. Soc. - 1990. - V.242. -P. 318-337.

22. Schechter, P. An analytic expression for the luminosity function for galaxies // Astrophys. J. - 1976. - V. 203. -P. $297-306$.

23. Takeuchi, T. T., Yoshikawa, K., Ishii, T. T. The Luminosity Function of IRAS Point Source Catalog Redshift Survey Galaxies // Astrophys. J. - 2003. - V. 587, Issue 2. - P. L89-L92.

24. Willott, C. J., Rawlings, S., Blundell, K. L., et al. The radio luminosity function from the low-frequency 3 CRR, 6 CE and $7 C R S$ complete samples // Mon. Not. Roy. Astron. Soc. 2001. -V. 322, Issue 3. - P. 536-552.

25. Wyder, T. K., Treyer, M. A., Milliard, B., et al. The Ultraviolet Galaxy Luminosity Function in the Local Universe from GALEX Data // Astrophys. J. - 2005. - V. 619, Issue 1. - P. L15-L18.

Надійшла до редколегії 27.04.16

S. Parnovsky, Dr. Sci,

I. Izotova, Ph. D

Astronomical Observatory of National Taras Shevchenko University of Kyiv

\section{INITIAL LUMINOSITY FUNCTIONS OF STARBURST GALAXIES}

For the sample of about 800 starburst galaxies the initial luminosity functions which appear the distributions of galaxy luminosities at zero starburst age are considered based on the data of luminosities of galaxies in the recombination Ha emission line in the regions of ionised hydrogen and the ultraviolet continuum. We find the initial luminosity functions for the starburst galaxies with Ha emission and ultraviolet continuum are satisfactory approximated with log-normal function.

С. Парновский, д-р физ.-мат. наук,

И. Изотова, канд. физ.-мат. наук

Астрономическая обсерватория Киевского национального университета

имени Тараса Шевченко

\section{НАЧАЛЬНЫЕ ФУНКЦИИ СВЕТИМОСТИ ГАЛАКТИК С АКТИВНЫМ ЗВЕЗДООБРАЗОВАНИЕМ}

На основе данных об излучении выборки 800 галактик с активным звездообразованием в рекомбинационной линии На в зонах ионизованного водорода и ультрафиолетовом континууме рассмотрены начальные функции светимости, которые описывают распределение светимостей галактик при нулевом возрасте вспышки звездообразования. Показано, что начальные функции светимости галактик с активным звездообразованием в рассмотренных диапазонах могут быть удовлетворительно представлены lоgнормальной функцией, которая удовлетворительно описывает и текущие функции светимости.

УДК 524.7

В. Жданов, д-р. фіз.-мат. наук, проф., С. Дилда, студ. фіз. ф-ту,

Київський національний університет імені Тараса Шевченка

\section{ЯКІСНИЙ АНАЛІЗ ЕВОЛЮЦІЇ ВСЕСВІТУ В ГІДРОДИНАМІЧНІЙ МОДЕЛІ 3 БАРОТРОПНИМ РІВНЯННЯМ СТАНУ}

Досліджено якісну поведінку масштабного фактора та густини енергії в гідродинамічній моделі однорідного ізотропного Всесвіту з загальним баротропним рівнянням стану (PC). Аналіз проведено за умов на РС більш загальних, ніж це було зроблено раніше у стаmmi [Jenkovszky et al., Phys. Rev. D 90, 023529 (2014)], зокрема, допускаються випадки з двома чи більше точками, де питома ентальпія космологічної рідини дорівнює нулю. Подано якісну класифікацію, яка включає можливі сценарії космологічної еволюції з асимптотично експоненційною інфляцією, аналоги "Великого розриву" у майбутньому чи у минулому, розв'язки без сингулярностей та осцилюючі всесвіти.

1. Вступ. Сучасна космологічна $\Lambda$ CDM-модель описує практично усі спостережні дані позагалактичної астрономії. Тим не менш, відомі проблеми горизонту та плоскостності вимагають шукати інші підходи для опису перших миттєвостей після Великого вибуху, пов'язаних з інфляційною стадією (див., напр., [1-4]). У сучасній космології відома низка явних аналітичних розв'язків, що описують еволюцію однорідного ізотропного Всесвіту. Але досить часто на перший план виходять якісні властивості космологічних сценаріїв, а саме: чи існує розв'язок для усіх часів, починаючи від космологічної сингулярності або він означений на скінченному інтервалі, коли прямують до нескінченності густина енергії або тиск і за яких умов тощо (див., напр., огляди в [5-8]). 3 цією метою в [8] було досліджено якісну поведінку розв'язків в гідродинамічній моделі однорідного ізотропного Всесвіту; баротропне рівняння стану, що розглядалося, було досить загальним, тим не менш, були застосовані певні обмеження щодо монотонності деяких складових цього рівняння. У даній роботі ми знімаємо ці обмеження і розглядаємо баротропне рівняння стану $p=p(e)$, яке пов'язує тиск $p$ та інваріантну густину енергії $е$ космологічної рідини лише за загальних умов однозначності та гладкості. Далі буде описано можливі сценарії космологічної еволюції в рамках цієї моделі в залежності від наявності коренів питомої ентальпії $h(e)=e+p(e)$, яку вважаємо гладкою функцією за усіх значень аргументу. Також припускатимемо, що $h(0)=0$.

2. Основні рівняння. Метрику простору-часу в однорідній ізотропній космології можна записати так:

$$
d s^{2}=d t^{2}-a^{2}(t)\left[d \chi^{2}+F^{2}(\chi) d O^{2}\right]
$$

де $F(x)=\sin (x), \sinh (x)$ або $x$ в залежності від параметру $k$, що може мати значення відповідно $1,-1$ або 0 (замкнений, відкритий або просторово-плоский Всесвіт).

Рівняння Фрідмана, що мають вид:

$$
\frac{d^{2} a}{d t^{2}}=-\frac{4 \pi}{3} a(e+3 p)
$$

